\title{
Energy Complex of a Municipality on the Example of Luleå (Sweden)
}

\author{
Alexander Stoyanov* \\ International Relations Department, Saint-Petersburg State University, St. Petersburg, Russia
}

\begin{abstract}
The following work focuses on the study of the energy complex in a particular country (Sweden) and in specific conditions (Luleå municipality in the first and second decades of the 21st century). The conclusions and results obtained during the work might be interesting from the point of view of applicability of practice in other countries, as an example of successful experience in implementing an effective fuel and energy complex, which allows each of the parties (producers and consumers) to derive the maximum mutual benefit. The main features of the energy economy of Sweden as a whole have also been considered, which may contribute to the deepening of research in this vein, in order to allow other municipalities to be considered, which in turn will make it possible to assess the efficiency and prospects of the fuel and energy complex in the country as a whole. The work also proposes and considers possible points of intensification of the production cycle in order to increase production capacities and improve the conditions for consumers who, due to the geographical features of the country's location, are forced to spend large amounts of money on innovative technologies, illustrated in consumer prices for electricity and heat supply (especially other municipalities in Sweden, for example, the difference between Luleå and them in terms of consumer prices can reach $30-40 \%)$.
\end{abstract}

\section{Introduction}

The energy system is one of the key aspects of modern international relations, which in many ways has begun to rely on the economic component. Therefore, the issue of efficient production, distribution and use of energy is becoming increasingly relevant. The environmental factor plays an important role here, it forces us to reconsider to some extent the aspect of production profitability, but also pay attention to another serious component - environmental safety. Sweden, which is today an extremely successful example of the implementation of environmentally friendly energy [2], seems to be a particularly interesting example for analysis. However, it should not be thought that this country is homogeneous from the point of view of the energy system - there are more successful and less successful examples [3]. Lulea should be considered as one of the most successful examples of the integration of all energy systems. So, according to the report, the lowest average price for electricity on the Nord Pool energy exchange among Swedish cities was recorded in Luleå (in 2016, 2017). There are explanations for this the municipality with the lowest price for electricity and heat, Luleå, has a long-established district heating network and has access to cheap excess energy from the SSAB steel factory. [1] Turning to the methodology of the current study, it is necessary to highlight such aspects of theoretical research as analytical, statistical methods, a systematic approach, and a number of others. The selected methods are collectively aimed at identifying current trends, identifying features (advantages and disadvantages), as well as identifying prospects in the area of the stated problems. In accordance with the stated relevance, the aim of this study is to analyze the energy system of the Luleå commune in order to identify advantages and disadvantages, as well as possible experience that can be adopted in this context. Accordingly, the following tasks were set:

1) determination of the main characteristics of the fuel and energy complex at the present stage;

2) identification of the main features of the energy sector in Sweden;

3) revealing the features of the energy of Lulea.

\section{Methodology}

In the course of this study, a number of methods was being used, aimed at detailed study of the issue. More specifically, an analytical and descriptive methods were used, as well as a systematic approach. The complex of these approaches made it possible to fully understand the structure and current trends in the functioning of the energy system of a particular municipality.

\section{Results}

As noted above, heat and power are supplied to the Luleå Energi district heating system. Part of the exergy

\footnotetext{
* Corresponding author: sa1516l19s@gmail.com
} 
is destroyed in the boiler and heat exchangers, and part is lost in the flue gases and during cooling. Part of the exergy is also exported to Bioenergi Luleå and to SSAB. [27] Losses and destruction of exergy are not included in this export. Work on the integration of processes to improve the efficiency of the system is currently being carried out using mathematical programming based on the MILP (Mixed Integer Linear Programming) tool, for further improvements it will require an improved tool ability to take into account the thermodynamic quality of energy flows [28]. A large amount of exergy is used to produce products that mainly need only a moderate amount of exergy. This means that it would be interesting to find ways to produce more valuable energy, such as electricity. This can be achieved by lowering the temperature of the hot water in the district heating system, using the released energy to generate more power. [29]

\section{Analysis}

\subsection{Energy system}

At the beginning of this study, it seems necessary to introduce the concept of an energy system - in the general sense it is the complex of energy resources of all kinds, as well as methods and means for their production, conversion, distribution and use, which provide consumers with all types of energy. The power system includes electric power, oil and gas supply, coal industry, nuclear energy and others. Usually, all these systems are combined nationwide into a single energy system, and across several regions into integrated energy systems. The integration of individual energy supply systems into a single system is also called the interindustry fuel and energy complex (FEC), it is due primarily to the interchangeability of various types of energy and energy resources. [7]

Often, a power system in a narrower sense is understood as a combination of power plants, electric and thermal networks, which are interconnected and connected by common modes of continuous production processes of conversion, transmission and distribution of electric and thermal energy, which allows centralized control of such a system. In the modern world, consumers are supplied with electricity from power plants, which can be located close to consumers or can be located far from them, at considerable distances. In both cases, electricity is transmitted through power lines.

However, in the case of remoteness of consumers from the power plant, the transmission has to be carried out at an increased voltage, and step-up and step-down substations should be built between them. Through these substations, with the help of electric lines, the power plants are connected to each other for parallel operation at a common load, also through heat points using heating conduits, this is also the way the heat and power plants and boiler rooms are connected but only at much shorter distances. The combination of all these elements is called a power system, it arises significant technical and economic advantages [7]: heat;

- a significant reduction in the cost of electricity and

- a significant increase in the reliability of electricity and heat supply for the consumers;

- increasing the efficiency of various types of power plants;

- reduction in the required reserve capacitance of power plants.

\subsection{Energy Complex of Sweden}

Hereafter the Swedish fuel and energy complex will be considered in general terms, after which the Luleo case will be regarded specifically. The basis of Sweden's energy economy today consists of four sources: oil and oil products, biofuels, hydropower and nuclear energy. Coal and natural gas occupy an insignificant place in the country's energy balance. Furthermore the role of wind energy is small today but it is growing rapidly. Sweden's energy supply in 2016 was as follows: 24\% hydropower, $24 \%$ atomic energy and $6 \%$ wind. In 2017, about 60 new wind turbines were added, and by the end of the year there were just over 3,400 wind turbines with a capacity of more than $50 \mathrm{~kW}$ each. Their energy production during the year has reached $200 \mathrm{MW}$ per each, and at the end in 2017, more than 6,700 MW of energy was produced. The remaining $46 \%$ of energy economy consists of approximately equal shares of fossil fuels and a combination of biofuels (i.e. vegetation) and waste. One third of Sweden's total energy consumption is in the form of electricity, this is $75 \%$ higher than the world average of $18 \%$. [8]

The most important energy resources consumed by industry are biofuels (38\%) and electricity (36\%). In addition to them, other important energy commodities for Sweden's industry are coal and coke (primarily for metallurgy) and petroleum products. [9]

Sweden's power industry is based on two main sources: hydropower and nuclear power. Both sources play an approximately equal role and together provide about $90 \%$ of electricity production. The topography and climate of Sweden contributed to hydropower: 47 hydropower plants with a capacity of more than 100 MW and 2057 hydropower plants in general. [8] Moreover, there are solutions which help to control hydropower - water left from rain and snow can be stored in tanks, this can help to intensify the production when the demand for electricity is the greatest (in winter). In addition, rain and snow constantly fill reservoirs throughout the year. In the times of dry years, production can be reduced to $50 \mathrm{TWh}$, and in rainy years to $80 \mathrm{TWh}$. In areas where there are no reservoirs or where they are too small, there is less control over the hydropower. Speaking about nuclear energy, Sweden has built 4 nuclear power plants, each of which consists of several reactors. A total amount of 12 reactors had been put into operation in Sweden gradually, between 1972 and 1985, with a total capacity reaching $11 \mathrm{GW}$. [10] This led to a rapid and significant reduction in CO2 emissions by about a third in just five years. The reactors has not been put into operation since 1985, and after 
2020 - half (i.e. 6 reactors or 38\% of the initial capacity of $11 \mathrm{GW}$ ) will be pulled out of service. The remaining $62 \%$ of capacity is expected to operate until at least 2040. Currently, 4 out of 6 reactors to be removed from service (22\% of the initial capacity) are deactivated, jining the number of 15 , which have already been permanently shut down. The fossil part of electricity production accounts for 25\% in 2017 compared with $75 \%$ in 1973 (these 25\% are generated by several cogeneration plants, but there are also few plants using fossil fuels (coal, oil, natural gas) as part of the energy reserve of Sweden). [8]

There has been a free electricity market in Sweden since 1996. This means that the buyer himself can choose an electricity supplier from among those on the market. The deregulation was carried out in order to ensure competition in the field of production and sale of electricity. Transmission networks remain state owned and are a regulated monopoly [11]. The main tool for trading electricity in Sweden, as in other Nordic countries, is the NordPool exchange. The NordPool exchange is Sweden's main electricity pricing tool. The NordPool spot prices (prices for electricity supply counted for the next day) are used as the accounting ones both for deliveries to industrial and individual consumers [12]. The functioning of the electricity market in Sweden in recent years has been sharply criticized by the energy consumers, both in industry and in the residential sector. The main reason for criticism is the high electricity prices [13].

Sweden's last unique aspect of energy supply is its relatively large $21 \%$ share of energy supply from biofuels and waste [14]. The production of this energy in Sweden is about $14 \%$ of waste and $84 \%$ of "primary solid biofuel". Solid biofuel is also known as biomass, which is simply vegetation, or a biological substance that was created as a result of photosynthesis. This term does not distinguish between slow-growing biofuels, such as trees, and fast-growing biofuels, such as grass [15]. About 55\% of Sweden's territory is occupied by forests, therefore it is not surprising that biofuels will be included in the country's energy system. $€ 1.68$ billion was allocated for biomass energy projects in Sweden in 2017 (bioelectric power plants in Borås, Upplands-Bro and Västerås; biomass plants in Östrand and Hyltebruk; commissioning of a biomass CHP in Sveg ; commissioning a thermal power plant in Bräkne-Hoby) [16]. Although Sweden has made significant efforts to decarbonize energy supplies, the share of energy from biofuels and waste has grown significantly, apparently without taking into account the associated carbon emissions. [10]

\subsection{Lulea Energy System: General Information}

Hereafter in the research the case of Luleå is referred to in order to emphasise its energy system picularities. The Luleå energy system consists of three main parts: the SSAB steel factory, the local LuleKraft combined heat and power production plant (CHPP), which uses the factory's process gases, and the Luleå Energi district heating system. [17]

Introducing a brief description of the mentioned objects, it seems necessary to note the following. The SSAB Luleå factory processes steel pellets from LKAB in Malmberget and Kiruna to about 200 different types of steel, each of which has different properties depending on the application. Each year, SSAB in Luleå delivers about two million tons of steel to the SSAB Bourlange plant for further processing.[18] SSAB has appeared in Luleå in 1950s at the as the metallurgical plant and Norrbottens Järnverk AB, which was stateowned until the late 1980s when it was listed on the stock exchange. The metallurgical plant was located in Lulea due to its proximity to iron ore. In the 1960s, production and sales increased, and the company became the second largest steel producer in Sweden with annual production of 400,000 tons and net sales of 60 billion SEK. [19]

The Lulea blast furnace is one of the 5 SSABs in the north. In the summer of 2015, the blast furnace was renovated after continuous operation for more than 15 years [20]. The renewal of the company's blast furnaces contributes to both increasing cost-effectiveness and reducing environmental impact. Repairs have reduced the costs and have halved dust emissions. The blast furnace, which was already one of the most economical in the world, is now reliable and ready for production for another 15-20 years. [21]

Luleå Energi was created in 1896, its steam generator, allowed to provide lighting among all the streets of the city. [22] Today, Luleå Energi sells and distributes electricity, Internet connections, bio-energy and central heating and cooling in Luleå. Luleå Energi is probably the most developed district heating system in Sweden. Within the city, all areas with larger objects are interconnected. It helps to connect separate zones, and all zones with direct electricity are converted into waterbased heating systems and district heating.

LuleKraft AB Power Station is a joint property of Luleå Energi and SSAB and provides most of Luleå's district heating and generates electricity. LuleKraft is a leading district heating player in Sweden.

\subsection{Lulea Energy System: Specific Features}

Now it is important to address to all the systems functioning within energy complex of the area. Process gases, coke oven gas (COG), blast furnace gas (BFG) and basic oxygen flue gas (BOFG) are generated on SSAB. [23] These energy-rich process gases are partly used in SSAB and partly sent to the LuleKraft CHPP, where they are burned in the boiler, generating steam at $520^{\circ} \mathrm{C}$, which enters the turbine system. Exiting the turbine system is a sequential process of the steam passing at $300^{\circ} \mathrm{C}$, at $95^{\circ} \mathrm{C}$, at $80^{\circ} \mathrm{C}$ and at $30^{\circ} \mathrm{C}$. It also generates about $80 \mathrm{MW}$ of energy. Steam at $300^{\circ} \mathrm{C}$ is the process steam, which used in SSAB. Steam with a temperature of $95^{\circ} \mathrm{C}$ and steam with a temperature of $80^{\circ} \mathrm{C}$ are used to produce heat through a two-stage heat exchanger, for example, for preheating hot water from 
$50^{\circ} \mathrm{C}$ to $90^{\circ} \mathrm{C}$ before being supplied to the district heating system. Then, the district heating system provides heating for the entire municipality of Luleå, about 700 GWh per year. The remaining steam condenses at the end of the turbine. All temperatures are approximate, but represent winter conditions.

The energy system is complex, and a global approach is needed to achieve energy efficiency. [24] Studies of the integration of processes in the Luleå system (SSAB LuleKraft - Luleå Energi) have been conducted for several years. The Luleå energy system has been partially designed, focusing on CHPP. The CHPP plant is interesting both from the point of view of exergy (water temperature is the dominant term of exergy) and from the point of view of industry, since costs can be reduced in Luleå Energi by lowering the temperature in the production line.

Exergetic fluxes throughout the system have been studied, and some possibilities for reducing exergetic losses are discussed. The thermal efficiency of the exergy SSAB, LuleKraft and Luleå Energi is 70\%, 40\% and $30 \%$, respectively. The relatively low exergy thermal efficiency is a natural consequence of the conversion of valuable chemical energy into water heating. In an integrated steel factory, exergy losses are caused by cooling the steel before transportation. At CHPP, exergy is destroyed mainly in the furnace. In district heating, exergy is destroyed mainly by the consumer. The preliminary conclusion is that a lot of exergy is destroyed and lost to produce hot water, which actually does not need so much exergy. By lowering the temperature of the water in central heating, most of the exergy can be converted to high-value electricity. Mapping using a combined energy / energy analysis is important for finding the ways to improve energy efficiency. It may also be important to start regional cooperation in the energy field. [25]

At a steel factory natural resources (mainly ore and coal) are used to produce steel. The main by-products of the steelmaking process are energy gases: coke oven gas (COG), [26] blast furnace gas (BFG) and basic oxygen flue gas (BOFG) [27]. These gases are partially processed at a metallurgical plant, and surplus is sent to LuleKraft CHP. LuleKraft produces electricity and hot water for central heating. Furnace flue gases are used to dry biomass in the Bioenergi Luleå wood pelletizing plant (not included in this study, energy content is not significant). Hot water from the CHPP is used for district heating (important in northern Sweden) in the entire Luleå region. If we look at the processes in a bit more detail, the energy gases (COG, BGF and BOFG) are mixed, and the result is called BLG ("blandgas" in Swedish). This BLG is used, sometimes enhanced by some high-energy COG. [28] A certain amount of oil is used for deflagration, and if a lot of heat is required (on cold days), additional oil is used as well. Oil and energy gases are burned in the boiler, and flue gases are used to pre-heat water. Some flue gases also enter the Bioenergi Luleå for drying biomass. Part of the steam is exported back to SSAB, part is used to generate electricity, and the remaining steam is used to heat water in central heating through two heat exchangers. The steam remaining at the end of the turbine system has a very low energy content and condenses into water. The huge amount of energy / exergy is being imported into LuleKraft from energy gases and oil. This is almost purely chemical energy and, therefore, exergy is equal to energy. [29]

\section{Discussion}

In accordance with the study, the definition of the fuel and energy complex was deduced and its main advantages compared with diversified production were indicated.

Speaking about Swedish energy sector as a whole, the main trends in energy production and processing were identified, so the main emphasis is made on the alternative sources - wind, water and biofuels. However, abandonment of previous practice is proceeding rather slowly, which can be especially noted for the presence of atomic generators and generators operating on the basis of gas, oil, and coal raw materials.

Finally, directly referring to Lulea, which is in the main focus of this work, it should be noted that the system of interdependence of enterprises used there, which allows to achieve maximum energy efficiency is still imperfect and can be further developed, it is expected that subsequent studies on this issue will make it possible to identify recommendations in more detail and modify what is now proposed. It should also not be missed the moment that the system built in Luleå is the most efficient in Sweden for a number of reasons, which generally allow to save the environment, while providing manufacturers and consumers the maximum benefit.

\section{References}

1. Energiforetagen, Elmarknaden, https://www.energiforetagen.se/globalassets/ene rgiforetagen/statistik/energiaret/energiaret2017_ elmarknaden_vers180614.pdf, last accessed 2019/10/15.

2. Sweden to become world's first fossil-fuel free nation,

http://www.climateaction.org/news/sweden_to_ become_worlds_first_fossil_fuel_free_nation\#t op, last accessed 2019/11/03.

3. Sweden Tackles Climate Change, https://sweden.se/nature/sweden-tacklesclimate-change/, last accessed 2019/11/04.

4. Grip, C., Dahl, J., Söderström, M.: Exergy as a means for process integration in integrated steel plants and process industries. Stahl Und Eisen 129 (2009)

5. Nilsson, K., Söderström, M.: Optimizing the Operating Strategy of a Pulp and Paper-Mill using the Mind Method. Energy 17, 945-953 (1992).

6. Linnhoff, B.: Pinch Analysis - a State-Of-TheArt Overview. Chemical Engineering Research \& Design 71, 503-522 (1993). 
7. Voropai, N., Claire, A., Kononov, Yu., Saneev, B., Senderov, S.: Methodological bases of system research on justification of development Fuel and energy complex and systems Energy in the works of MESI SB RAS. System studies in the energy sector: methodology and results, 48-53 (2018).

8. World Energy Data, The Energy System of Sweden,

https://www.worldenergydata.org/sweden/, last accessed 2019/10/09.

9. Grip, C.-E., Söderström, M., Berntsson, T.: Process integration as a general tool for energy intensive process industry. Development and practical applications in Sweden. In: 3rd International Conference on Process Development in Iron and Steelmaking, Luleå (2008).

10. GIS EE, Fuel and Energy Complex of Sweden, https:/gisee.ru/articles/ foreign_politics/28105/, last accessed 2019/10/13.

11. Cruciani, M.: The Energy Transition in Sweden. Études de l’Ifri, Paris (2016).

12. Maintaining electricity security across the Nord Pool market, https://www.ceer.eu/documents/104400/-//9b640235-a0af-a7c4-9d5b-da87928963a6, last accessed 2019/11/03.

13. Sweden's Lack of Electricity Capacity Is Threatening Growth, https://www.bloomberg.com/news/articles/2019 -05-03/sweden-s-lack-of-electricity-capacity-isthreatening-growth, last accessed 2019/11/04.

14. 2017 another record year for biofuels in Sweden,

https://bioenergyinternational.com/marketsfinance/2017-another-record-year-biofuelssweden, last accessed 2019/11/03.

15. IEA Bioenergy Countries' Report - Update 2018, Bioenergy policies and status of implementation,

https://www.ieabioenergy.com/wpcontent/uploads/2018/10/IEA-BioenergyCountries-Report-Update-2018-Bioenergypolicies-and-status-of-implementation.pdf, last accessed 2019/11/04.

16. Over EUR 1.68 billion worth of biomass power projects in Sweden, https://bioenergyinternational.com/heatpower/eur-1-68-billion-worth-biomass-powerprojects-sweden, last accessed 2019/11/03.

17. Elfgren, E., Grip, C-E., Wang, Ch., Karlsson, J.: Possibility to Combine Exergy with other Process Integration Methods for a Steelmaking Case. Chemical Engineering Transactions, 1374-1380 (2010).

18. Zetterberg, L.: Flows of Energy and Exergy in the Steelmaking process at SSAB Luleå. Master's Thesis, Göteborg (1989).

19. Northsweden, SSAB, https://www.northsweden.eu/nyheter/2015/ssab/ , last accessed 2019/10/08.
20. SSABs renoverade masugnar sänker kostnader med $200 \mathrm{Mkr}$ årligen, https://www.ssab.se/ssabkoncern/nyhetsrum/nyhetsarkiv/2015/11/04/07/ 03/ssabs-renoverade-masugnar-s\%C3\%A4nkerkostnader-med-200-mkr-\%C3\%A5rligen, last accessed 2019/11/03.

21. Energiforetagen, Kraftvärme, https://www.energiforetagen.se/sa-fungerardet/kraftvarme/, last accessed 2019/10/15.

22. OPTi, Luleå Energi AB, http://www.opti2020.eu/samplepage/consortium/lulea-energi-ab/, last accessed 2019/10/08.

23. Larsson, M., Grip, C.-E., Ohlsson, H., Rutqvist, S., Wikström, J.-O., Ångström, S.: Comprehensive study regarding greenhouse gas emission from iron ore based production at the integrated steel plant SSAB TUNNPLAT AB. International journal of green energy. vol. 3, nr. 2, 171-183 (2006).

24. Luleå Energi AB, Fjärrvärme - det bara funkar helt enkelt, https://www.luleaenergi.se/sv/privatkund/fjarrv arme/fjarrvarme/, last accessed 2019/10/09.

25. Wall, G.: Exergy tools. Proceedings of the Institution of Mechanical Engineers Part A Journal of Power and Energy 217, 125-136 (2003).

26. Larsson, M., Sandberg, P., Söderström, M., Vuorinen, H.: System gains from widening the system boundaries: analysis of the material and energy balance during renovation of a coke oven battery. International Journal of Energy Research, 1051-1064 (2004).

27. Malmström, S.: Efficient use of waste energy in the steel industry. Master thesis, Luleå (2009).

28. Elfgren, E., Grip, C-E., Wang, Ch., Karlsson, J.: Exergy as a means for Process integration in an integrated Steel plant. Stahl und Eisen, 1-6 (2007).

29. Linnhoff, B., Hindmarsh, E.: The Pinch Design Method for Heat-Exchanger Networks. Chemical Engineering Science 38, 745-763 (1983). 